\title{
Examining the U.S. premed path as an example of discriminatory design \& exploring the role(s) of capital
}

\author{
Barret Michalec ${ }^{1} \cdot$ Frederic W. Hafferty ${ }^{2}$
}

Accepted: 11 January 2022 / Published online: 2 February 2022

(C) The Author(s), under exclusive licence to Springer Nature Limited 2022

\begin{abstract}
The college-level pathway to medical school (i.e., the "premed path") includes all coursework, extra-curriculars, shadowing, volunteering, high-stakes examination (e.g., MCAT®), and application-related processes. Although medical school admission committees routinely insist their interest in diverse and "well-rounded" applicants, the premed path (PMP), through formal and informal mechanisms, is constructed to favor those from high in socioeconomic status (SES) privileged backgrounds, and those majoring in typical premed majors such as in the Biological Sciences. In these respects, the PMP is an example of Discriminatory Design-an entity constructed and sustained in a manner that (un)intentionally discriminates against certain groups of individuals. We begin this paper by providing a brief description of the PMP (within the U.S. specifically) and conceptual and theoretical overview of the discriminatory design framework. We then explore how the PMP is an example of discriminatory design through the distinct but related role(s) of financial, social, cultural, and (what we term) (extra)curricular capital. Using data gleaned from interviews with premedical students, content analyses of the curricular structure of particular majors and publicly available data on the various "costs" associated with the PMP, we detail how the PMP is reflective of discriminatory design, spotlighting specific barriers and hurdles for certain groups of students. Given the persistent lack of representation of students from minoritized groups as well as those from diverse academic backgrounds within medical schools, our goal is to spotlight key features and processes within the PMP that actively favor the pursuit of certain majors and students from more privileged backgrounds. In turn, we conclude by offering medical schools and undergraduate institutions specific recommendations for remediating these barriers and hurdles.
\end{abstract}

Keywords Premed $\cdot$ Capital $\cdot$ Discriminatory design $\cdot$ Medical education

Barret Michalec

barret.michalec@asu.edu

1 Arizona State University, Phoenix, AZ, USA

2 Mayo Clinic, Rochester, MN, USA 
We're not taught to be humanistic, well-rounded medical students, we're not even taught to think about what kind of doctor we want to be. We're taught to get good grades, do well on the MCAT and get into a good medical school. I don't think it's the students' fault or the faculty's fault. It's just a difference in priorities in the curriculum and the requirements. (4th year premed student).

\section{Introduction}

\section{The structure of the U.S. premed path (PMP)}

Particular aspects of the pre-medical experience (i.e., the before medical school) such as timing, duration, requirements, and associated costs can vary by country. Therefore, in order to provide a clear and concise perspective on the structure of and experiences within the premedical realm we focus specifically on the premed path (PMP) within the United States (U.S.). Although this approach may be Westerncentric, exposing features and processes of the U.S.-specific premed path may yield valuable insights into related and similar elements of other countries' premedical systems. Within the U.S., the PMP is the college-level pathway to medical school that includes all coursework, extra-curriculars, shadowing, volunteering, high-stakes examination, and application-related processes.

According to the recent Medical School Application Requirements (MSAR) (AAMC Staff 2018), a majority of U.S./North American medical schools require the same credits/semester hours in Biology, Chemistry, and Physics, e.g., 6-8 credit hours (with lab) in biology (with lab), 6-8 credit hours in general or inorganic chemistry (with lab), 6-8 credit hours in organic chemistry (with lab), and 6-8 credit hours in the physical sciences (with lab). At a typical undergraduate institution, these credit hour requirements constitute about 8 individual courses, with lab-based requirements tied to specific courses. In addition to these science-specific course requirements, medical schools also require at least 2 college-level courses in English, at least 1 college-level course in math (often calculus or statistics). Medical schools may also "strongly recommend" (if not explicitly require) courses in genetics, biochemistry, anatomy \& physiology, social determinants of health, ethics, and/ or psychology (AAMC Staff 2018). The PMP also includes course requirements associated with students' particular undergraduate major(s) (and possible minors), as well as courses required by undergraduate institution itself (e.g., University and/ or College-specific "breadth" requirements).

Premed students must also prepare for, schedule, and take the Medical College Admission Test ${ }^{\circledR}$ (MCAT $\left.®\right)$, a standardized, multiple choice exam utilized by medical school admission committees to asses students' “..problem solving, critical thinking, and knowledge of natural, behavioral, and social science concepts and 
principle prerequisite for the study of medicine." (AAMC 2020a) The $7 \mathrm{~h}$ 30-min MCAT® exam ${ }^{1}$ consists of 230 questions within 4 distinct but related sections: (a) Biological and Biochemical Foundations of Living Systems, (b) Chemical and Physical Foundations of Biological Systems, (c) Psychological, Social, and Biological Foundations of Behavior, and (d) Critical Thinking and Reasoning Skills.

Beyond specified coursework and the MCAT®, there are shadowing and volunteering requirements associated with the PMP. Shadowing is observing a healthcare professional (e.g., physician) engaging with patients, colleagues, and in general day-to-day activities associated with their profession (Kitsis 2011; Kitsis and Goldammler 2013). The goal of shadowing is for premed students to attain a fundamental understanding of what a physician "does" and the setting(s) of healthcare delivery. The number of shadowing hours required vary by medical school, but premed advisors at the institution where this study occurred suggest that students log at least 50 shadowing hours. The goal of volunteering is for students to showcase a commitment of service, and engage in service activities in clinical and community settings. Much like shadowing, the number of volunteer hours required varies by medical school.

Finally, students on the PMP must also consider the time, effort, and "space" needed to potentially engage in research activity, participate in beneficial extra-curriculars (e.g., clubs, student organizations, athletics, hobbies, etc.), as well as complete all application-related materials (e.g., personal statement, C.V., and essays).

All of these requirements and "recommendations" make it necessary for premed students to be preemptively and perpetually strategic in mapping out their curricular pathway in order to complete all the requirements (medical school, major, College, University) in a timely fashion, as well as to identify where in their schedule there may be time and "space" to engage in non-curricular requirements and opportunities. The structural design of the PMP is not only quite rigid but also firmly institutionalized as previous literature shows that the science-specific admission requirements are remarkably similar to those required 90 years ago (Dalen and Alpert 2009; Barr 2010).

There have been extensive examinations of various elements of premedical education including curriculum design/requirements (Kanter 2008; Barr et al. 2010; Hirshfield et al. 2018), aspects of dehumanization (Conrad 1986; Coombs and Paulson 1990; Sampson et al. 2020), and nested financial challenges (Steven et al. 2016; Baugh et al. 2019; De Freitas et al. 2021), among others. Moreover, Lin and colleagues provide a broad overview of the PMP literature, as well as an in-depth exploration of narratives from U.S. premed students (Lin et al. 2013; Lin et al. 2014). Nonetheless, there remains a critical need for a more theoretically grounded explanatory approach to unearth and address institutionally embedded processes and mechanisms that may perpetuate the lack of inclusion and equity within this arena of health professions education. For example, De Frietas et al.'s (2021) recent

\footnotetext{
1 This is the pre-COVID-19 standard time frame of the MCAT® exam. Given various constraints and challenges stemming from the global pandemic, the AAMC shorted the total "seated" time from $7 \mathrm{~h}$ and $30 \mathrm{~min}$ to $5 \mathrm{~h}$ and $45 \mathrm{~min}$ for exams administered from May 29, 2020 through the end of the 2020 testing cycle. The number of questions on the exam remains the same.
} 
work showcases the utilization of individual/group-level theories to examine the admission experiences of aspiring physicians from low-income backgrounds (in Canada). Alternatively, we argue here that systems- and structural-level theories will be more effective in addressing persistent and consistent institutional barriers and hurdles within premedical education and medical school admissions in that individual behaviors, choices, and perceptions are heavily influenced (if not determined) by social-structural factors. To this end, we deploy two theoretical perspectives to explore the design and impact of the PMP: (1) Benjamin's work on discriminatory design and (2) Bourdieu's work on capital.

\section{Discriminatory design: background \& relation to the U.S. PMP}

Discriminatory design is the fashioning and fabrication of physical and social entities that can (intentionally or not) negatively affect particular groups of people, and in turn, sustain power and status differentials nested within social hierarchies (Benjamin 2019). The term most often has been employed in the fields of industrial and architectural design including public "seating" (e.g., public benches designed to make sleeping/laying down more difficulty), public transportation systems, and neighborhood zoning laws (Schindler 2015; Groeger 2016; Jones 2018). Benjamin $(2015,2019)$ discusses the ways in which discriminatory design is nested within the structure, processes, and practices of science, medicine, and technology-to the detriment of already marginalized groups, particularly minorities, and to the benefit of preexisting hierarchical structures and power and status dynamics, prejudices, and stigmas. In these respects, Benjamin overlays the impact of physical, architectural design on social-structural design, and thus how the explicit/implicit structure of "things" can reflect and negatively impact social structures.

In this study, we extend the notion (and application) of discriminatory design theory to another social structure (and the processes nested therein), the premedical path (PMP). We argue that the "architecture" of requirements and recommendations including (but not limited to) courses, shadowing and volunteering hours, and the MCAT®—collectively deployed by the medical school admission committees and sustained/enforced by undergraduate advising groups/committees-actually discourages students from minoritized groups and underprivileged backgrounds as well as students interested non-traditional premed majors (e.g., social sciences and humanities $\left(\mathrm{SSH}^{2}\right)$ from pursuing and/or continuing the PMP. In these respects, a discriminatory design frame substantially modifies the "leaky pipeline" metaphor often utilized in discussions of how and why students from minoritized groups may leave the STEM fields (including premed) during the undergraduate years (Barr et al. 2008; Atkin et al. 2002; Alexander et al. 2009; Linnenbring-Garcia et al. 2018). We argue that this "leaky pipeline" metaphor is incomplete and suggests a process that is overly passive and incidental with minimal, if any, culpability at the institutional level. Utilizing the discriminatory design framework pushes us to view

\footnotetext{
2 The humanities include areas of study such as Art, English, History, Literature, Music, Philosophy, and Religion. The social sciences include areas of study such as Sociology, Economics, Political Science, Psychology, and Anthropology.
} 
the PMP as an entire plumping system rather than one or two "faulty pipes." Furthermore, the discriminatory design perspective, as a theoretical lens, can spotlight structural-level implicit and explicit exclusionary practices, mechanisms, and processes nested within the PMP, which is essential to not only identifying but also authentically addressing inclusion and belonging in medical education and the medical profession.

\section{The role of capital in the U.S. PMP: financial, cultural, social, \& (extra)curricular}

To further emphasize and reinforce the discriminatory design perspective, we utilize Bourdieu's theoretical concept of "capital" (Bourdieu 1986). According to Bourdieu, all human activity occurs within socially constructed fields (various arenas of discourse and activity, e.g., the PMP) and within each field particular aspects of capital are recognized as more valuable (i.e., having more clout or higher degree of "social currency") and therefore the accumulation and conservation of aspects of capital is considered advantageous (Carrington and Luke 1997). In turn, the gathering, sustaining, and strategic utilization of forms of capital dictate an actor's social position within the various fields they encounter and engage with. Specific to this study, reviewing the architecture of the PMP with this lens allows us to dissect how this architecture may actually "work" actively and passively to discriminate particular groups of students. By overlaying the capital framework on the discriminatory design perspective, we show the mechanisms by which the PMP disadvantages particular groups of students, and in some cases, both restricts entry to or actively pushes them off the path. In this sense, think of discriminatory design as the various components of a clock, and the notion of capital as the mechanics of its gears.

In approaching the PMP in the context of "capital," we view (a) financial (economic) capital as monetary-based funds needed and utilized to pay for goods and services related to various aspects of medical school admissions and the progression through the PMP; (b) cultural capital as the accumulation of knowledge, behavior, and skills in knowing how to "play the game," having a map, compass, and advice from guides to effectively navigate the premed realm and medical school admissions process, and (c) social capital as the presence and utilization of interpersonal relationships and group connections (i.e., social networks) that can provide emotional, social, and informational support. In these respects, we are utilizing simplified conceptualizations of Bourdieu's classic conceptualizations of forms of capital (Bourdieu 2018) to explore their role and presence within the PMP. ${ }^{3}$ As in society at large, and also within the PMP, all three forms of capital are unevenly distributed and usually inherited. As such, premed students from minoritized groups including racial and ethnic minority students, first-generation college students, and those students from lower socioeconomic status are at an immediate and persistent disadvantage compared to their more privileged peers as the PMP is riddled with more financial, social, and cultural capital-related "costs," hurdles, and barriers.

\footnotetext{
3 A clarifying point moving forward, capital is a property of individuals, not of pathways.
}

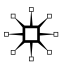


To this trilogy, we also introduce a new archetype of "capital"-(Extra)Curricular Capital. Similar to other models of capital that outline how particular societal elements have more (or less) "value" or "worth," the concept of (extra)curricular capital denotes how certain courses, majors/minors, research endeavors, outsideof-class opportunities (e.g., shadowing and volunteering), and even hobbies are of higher status, and "value," and carry more "currency" within the PMP. As no form of capital is fully interdependent of the others, (extra)curricular capital is consociated with financial, cultural, and social capital. We argue that this is a novel form of capital, and not merely a signal or artifact of cultural, social, and/or financial capital, in that (extra)curricular requires an ability to (a) decipher the difference between what medical schools actually value and what they say they value and (b) identify and acquire what specific medical schools are looking for regarding the nuances of certain requirements. To this end, we consider (extra)curricular capital to be reflective of aspects of cultural capital (i.e., knowing how to "play the game"), and social and financial capital (i.e., having the resources (broadly speaking) to know about, identify, and acquire such opportunities), yet also requiring an ability to translate elements of the hidden curriculum of medical education (Michalec and Hafferty 2014) and reading the tea leaves of organizational context and socio-cultural nuances promoted by certain medical schools (e.g., through their mission statements, as well as through the design and information featured in/on their website and promotional material). For example, shadowing is a requirement for a majority of medical schools, however, there is variation among medical schools as to the metrics and structure associated with that requirement (i.e., number of hours and who can be shadowed). Knowing that there is a shadowing requirement, identifying specific shadowing opportunities, and the ability to participate in those opportunities (i.e., transportation and schedule) all reflect aspects of cultural, social, and financial capital. But knowing what specific medical schools are looking for regarding the type of shadowing experiences (i.e., clinics serving low-income and or immigrant patient populations, those focusing on women's health, contact with particular specialties, showcasing experience with various health professions (not just physicians), etc.) is a distinct form of "capital"-(extra)curricular capital. This capital skill set extends to volunteer activities as well knowing what specific schools are looking for, and knowing that particular experiences will most likely carry more value/worth to these medical schools. In short, (extra)curricular capital relates to the ability to decipher the space between what medical school admissions committees formally state for requirements and what they (informally) are looking for. In the case of shadowing, for example, (extra)curricular capital is more than social, cultural, and financial capital in that it is not just knowing that you need to shadow and identifying shadowing opportunities - it is understanding not only who can be shadowed, but who should be shadowed, and acquiring those opportunities.

Similarly, regarding coursework and the PMP, knowing which courses are required to apply to a majority of medical schools, acquiring the materials for those courses, and achieving "success" in these courses are all reflective of social, cultural, and financial capital. But, understanding what other courses (e.g., courses "recommended" but not "required" by medical schools) carry more value/worth for certain medical schools, and navigating the cost-benefit analysis of time, effort, and 
potential impact on GPA associated with those courses, and purposely enrolling or not enrolling in those courses to strategically enhance one's application is reflective of (extra)curricular capital.

Those students steeped in (extra)curricular capital tend to curry favor with medical school admission committees in regard to required and/or recommended coursework, shadowing and volunteering experience, and even leisurely pursuits that align with medical school's perceptions of "well-roundedness." In turn, they have a pronounced opportunity to stand out and be "unique" as an applicant. Within this study, we focus primarily on science-based majors (e.g., Biology) and shadowing/volunteering opportunities as prime examples of (extra)curricular capital within the PMP.

There has been extensive research regarding the financial costs associated with applying and attending medical school (Walsh 2014; Kerr and Brown 2006; Greysen et al. 2011; Millo et al. 2019). This anticipated cost can be daunting, leading some premed students to step off the PMP even before the application process (Lovecchio and Dundes 2002). In addition, there are numerous other "costs" and "tolls" requiring forms of capital peppered along the PMP that receive far less attention, but nonetheless have significant impact on premed students' ability and willingness to continue through the PMP. Within the field of the PMP, the forms of capital take shape as (a) having the monetary funds to pay for the MCAT® and related preparation materials, medical school applications and interviews, undergraduate and medical school tuition and fees, books, supplies, etc. (i.e., financial capital), (b) having (at the ready or clear access to) a "map" or a trove of knowledge and information regarding how to effectively and efficiently navigate the PMP (i.e., cultural capi$t a l)$, (c) having an active and available social network of connections within medical school, medicine, and/or healthcare delivery institutions (i.e., social capital), and (d) pursuing typical premedical majors as well as having opportunities and experiences that align with institutionalized medical school requirements and recommendations (i.e., (extra)curricular capital). We argue that the PMP in its design and structural stasis is actually discriminatory towards students not steeped in these forms of capital. The conjoint use of a discriminatory design framework with a keen focus on the role(s) of capital allows us to consider the PMP as a structural design issue and thus discriminatory practices, processes, and outcomes more a matter of structure than intent.

\section{Methods}

Through the theoretical lens of discriminatory design and capital, we bring together three distinct data sources in this multi-method study to identify potential (explicit and implicit) exclusionary practices, processes, and mechanisms nested within the PMP. Multi-method approaches can overcome individual method's limitations and produce a more comprehensive picture of the investigated social phenomena by combining information from complementary data sources and, in turn, enhance the strength and rigor of the study (Brewer and Hunter 2006; Seawright 2016). Given the lack of empirical research on the PMP (Michalec et al. 2018) as well as the relative absence of the student-voice within the dearth of PMP research, our goal 
through the multi-qualitative-method approach is to present a more encompassing perspective of the structure of and experiences within the PMP.

Although primarily an approach to mixed-methods study (i.e., studies that "mix" quantitative and qualitative approaches), we employ a triangulation design (Morse 1991; Creswell et al. 2003) by converging non-overlapping qualitative methodological approaches (of differing strengths and capacities) to better explore the design and features of the PMP. The triangulation design is an effective approach to collecting and analyzing each type of data separately. This facilitates the corroboration of findings, insightful and thorough interpretations, and well-substantiated conclusions (Creswell et al. 2003). Through interviews with premedical students, we explore how students (from various backgrounds) experience the PMP, as well as their perspectives of barriers, hurdles, and facilitators nested within the PMP. By analyzing the "content" associated with specific majors (at the study location), we compared the courses of these majors with the courses required (and recommended) by most medical schools. We also examined websites associated with various aspects of the PMP and medical school application process in order to present the range of costs associated with the PMP.

\section{Interviews with premedical students}

To amplify premed students' voices and better understand their perspectives on the processes and mechanisms nested within the PMP, we interviewed 35 premedical students from a mid-sized, mid-Atlantic public University between 2017 and 2018. Purposive sampling was utilized in order to gather a sample of premedical students that was representative demographically (including major) to the national population of medical school applicants (as provided by the AAMC website (AAMC 2019a)). Third- and Fourth-year students were intentionally over-sampled (71\% of sample) as these students had experienced more of the PMP (i.e., courses, shadowing and volunteer requirements, MCAT, submitting applications, etc.). However, the sample does include more premed students from racial and ethnic minority groups, specifically Black premedical students, compared to the national average in order to explore the experiences and perceptions of these students, which is often lacking in the literature. Potential participants were approached via an email outlining the nature of study, that it was completely voluntary, and what participation would entail. These solicitation emails were sent to premed-specific registered student organizations, and students were instructed to contact the lead author if they were interested in participating. The 35 students that were interviewed provided selfreported data regarding the followed sociodemographic categories (on brief presurvey questionnaire that included particular demographic questions): $31 \%$ white, 29\% Black or African American, 14\% Asian, 14\% Middle Eastern or Indian, 6\% Latino, 3\% Multiracial, and 3\% (1 participant) did not report their race or ethnicity. Of the 35 participants, 25 were currently in their 3rd or 4th year of undergraduate education, and 16 were male, and 19 were female. A majority of participants reporting majoring in the Biological Sciences (20) with others reporting majoring in the Physical Sciences (4), Social Sciences (2), Humanities (1), and within specialized 
health sciences (4). Finally, 4 participants major in "other" disciplines. Participants were asked questions regarding their coursework, extra-curriculars, perspectives on and experiences with the application process, thoughts regarding admission requirements and recommendations, and general thoughts on being a premed student. The lead author's IRB granted the use of human subjects for this specific study.

Interviews were transcribed and then analyzed via deductive and inductive techniques in a multi-stage process (Miles and Huberman 1994; Kvale and Brinkmann 2009). First, interviews were analyzed using the following broad deductive codes: Science, Social Science, Humanities, Requirements, Shadowing, Volunteering, Admissions, Application, MCAT, Major, Minor, among others. Interviews were then analyzed using the tenets of financial, cultural, social, and (extra)curricular capital, and related terms, to more thoroughly examine the potential "presence" and role(s) of these concepts within the students' experiences and perceptions. Examples of broad terms employed as deductive codes in this stage include (but are not limited to) Knowledge, Relationships, Understanding, Previous Experience, Choice, Decision, Cost/Expense. Next, inductive coding was used to allow the data to speak for itself and provide a more granular understanding of these premed students' perceptions, experiences, and attitudes. We identified specific categories and foci through these initial analyses (e.g., Strategic Choices, High Costs, Disparities, among others), with these concepts then utilized as codes themselves with "clean" versions of transcripts to re-analyze the data.

\section{Content analysis: majors, premed requirements, and costs of PMP}

To better understand the structure of the PMP, as well as explore the potential overlap (or lack thereof) of medical school requirements and requirements for specific majors, we examined the formally required coursework for the Biology, Sociology, and Philosophy majors at the University where this study was conducted (Sociology and Philosophy are representative of the SSH disciplines). We then compared these course lists to the standard required courses for medical school admissions. We believe the course-structure for these majors is not specific to the University featured in this study, and most likely reflect the common structure of the requirements associated with these majors at a majority of public and private undergraduate institutions.

Finally, and in order to better understand the various costs associated, the PMP and medical school admissions, we also conducted content analysis of various premedical, medical school admissions, and testing-specific websites. 


\section{Results}

Given the triangulation design of data collection and analysis, as well as the deductive analysis techniques employed within the interview data specifically, we present the findings by category of Capital. ${ }^{4}$

\section{Financial capital}

The AAMC (2020b) outlines expenses related to medical school tuition and related costs of fees and health insurance. Within the PMP itself, however, annual cost of college textbooks and materials is about $\$ 1300$ (CollegeBoard 2020) and all students interviewed for this study noted that the books and supplies associated with their science-based courses and related labs sections were much more expensive than those associated with their non-science courses.

The MCAT $\AA$, in turn, costs $\$ 320$ to take and have your scores distributed to medical schools (AAMC 2020c). Furthermore, there are additional fees for late registration, changes to the registration, and testing at international test sites. In addition, rescheduling the MCAT® exam will cost students between $\$ 95$ and $\$ 160$ per reschedule depending on how far out the original exam date is/was (Kaplan, n.d.a). According to Kaplan (n.d.b), between 2015 and 2017, about 24\% of students took the exam more than once, but according to the 4th year students we interviewed, most students will reschedule their MCAT® at least once because they underestimated the amount of time they needed to prepare.

There also are appreciable costs associated with MCAT® preparation. Table 1 breaks down the costs per material/program offered by three popular MCAT® prep companies. A majority of the premed students interviewed for this study (who had taken the MCAT®) noted that they purchased a "whole package" (books, online resources, AAMC resources, question banks, set courses, etc.) from one companywith some turning to another company's materials when they felt the initial package did not work for them. In addition, most students mentioned enrolling in at least one additional course-based program (online or in-person). Students did try to utilize "used" versions of books and other materials, but most students purchased completely new test-banks to start with.

During the interviews, students consistently expressed their concerns regarding the financial costs associated with taking the MCAT®

"Like the MCATs are catered to people who have an advantage, so people who can afford to take certain courses, and spending five thousand dollars to have a tutor so that they can do well. I just think that part of it is really frustrating." (3rd year Premed)

\footnotetext{
${ }^{4}$ The results presented in this section are pre-COVID-19 and are therefore reflective of the more typical/ traditional premed path experience. Because of and in response to the impact of COVID-19, there have been changes in costs of MCAT® prep materials and the MCAT® test itself, interview procedures (i.e., virtual), even shadowing and volunteering requirements. Moreover, given the nature of the pandemic, and related shifts in state-based responses, more changes can most likely be expected.
} 


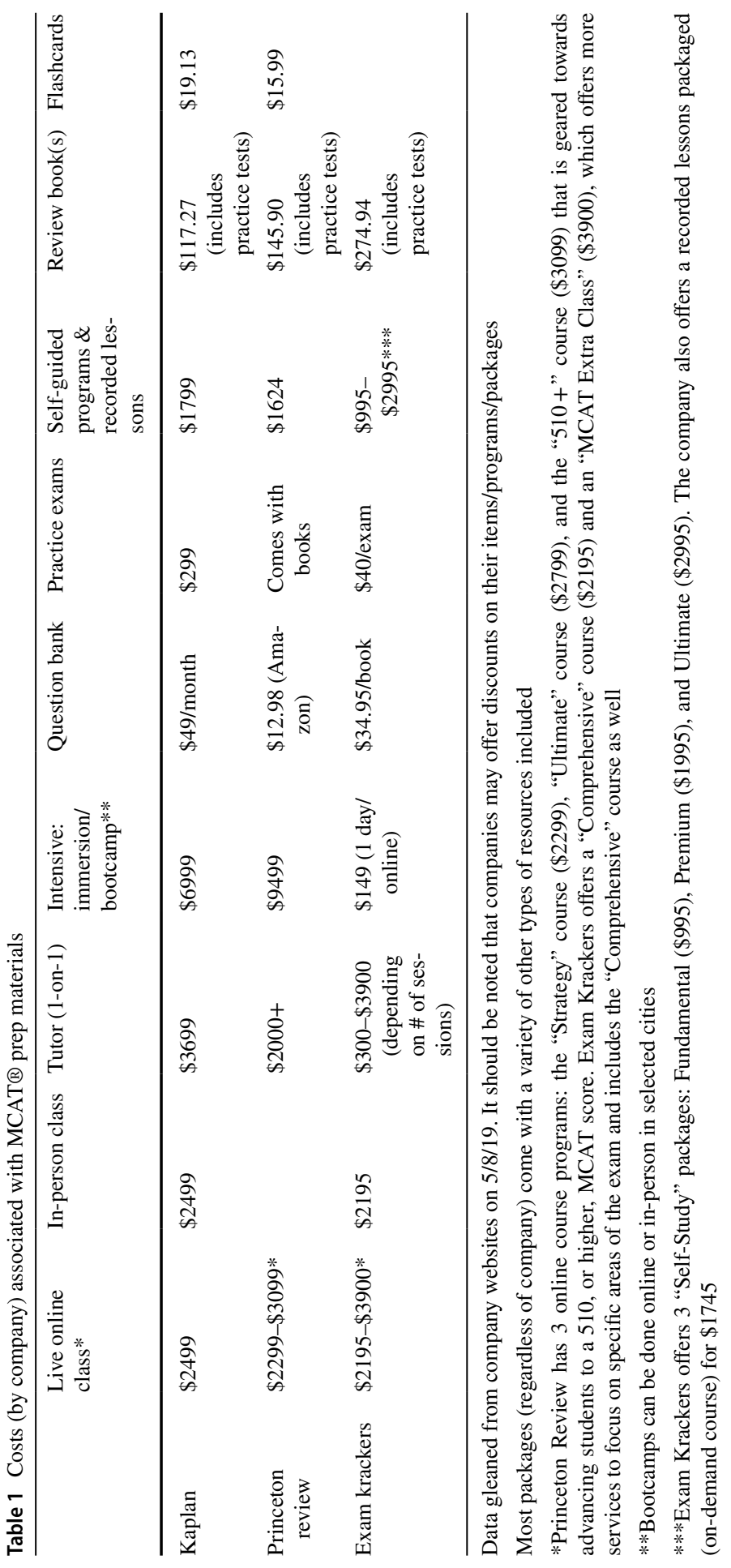

象 
"I'm concerned about the financial aspect of it because I know it costs...I heard it costs like $\$ 300$ per MCAT, and I heard people spend thousands of dollars just applying to medical schools, and I know medical school itself is very expensive. It's not just about my grades, it's about my wallet." (2nd year Premed)

According to premed advisors, students should plan on spending about $\$ 3000$ on application fees alone (Swarthmore 2020). Dissecting this, the American Medical College Application Service® (AMCAS®) charges approximately $\$ 170$ for applying to the first school, and $\$ 40$ for each additional school (AAMC 2020d). Similarly, the American Association of Colleges of Osteopathic Medicine (AACOMAS®) charges $\$ 196$ for the first school, and \$46 for each additional school AACOM, n.d. To attach their official transcript to their application will cost students about \$7-\$11, and if you apply to both MD and DO programs, you will have to send your official transcript twice because DO programs utilize a different application system (i.e., AACOMAS®). Sending the "results" of their CASPer, the Computer-based Assessment for Sampling Personal characteristics, to medical schools costs about $\$ 10$ per school. If students are requested to submit a secondary application, these can cost between $\$ 100$ and $\$ 130$ per school (depending on the school) and many medical schools have additional fees associated with their secondary applications. And even before all this application process begins, a majority of premedical students purchase access to the MSAR ${ }^{\circledR}$ (Medical School Admissions Requirements ${ }^{\mathrm{TM}}$ ) from the AAMC to learn more about schools, their admission standards, and help decide which programs they should even apply to-this costs $\$ 28$. These quickly accumulating costs are unavoidable, unevenly impact premed students from lower SES backgrounds, and may impact where and to how many schools you may apply.

Not surprisingly, there are private academic consulting companies (e.g., AcceptMed, Cracking Med School Admissions, Med School Coach, Be Mo Academic Consulting, among others) that offer assistance with various elements of the medical school application and admission process including general application, interview (including MMI), personal statements, application-related essays, CASPer, and even soup-to-nuts full application and admissions consulting. These programs/packages can range from about $\$ 150$ to $\$ 9500$.

Premed students also face interview-related costs. These can include (but are not limited to) travel, lodgings, food, and possibly even new attire for the interview process. Most often, premed students pay these costs out-of-pocket, and because interviews are a key aspect of the medical school admissions, it is unlikely that students will decline an interview opportunity, in turn making most of these costs unavoidable. Finally, and perhaps ironically, if the student is admitted to medical school, they are most likely required to submit a deposit, anywhere between $\$ 500$ and $\$ 3000$ (which is often rolled in their tuition), within weeks of their notification of acceptance, to "secure" their seat at that institution (Powell and Korwarski 2020). 


\section{Social \& cultural capital}

From the interviews we found that evidence of costs associated with social and cultural capital were appreciably intertwined and reflected the availability, acquisition, and sharing (or lack thereof) of key resources (including information) necessary to effectively and efficiently navigate the PMP. Moreover, concerns related to the challenges and struggles related to social and cultural capital were expressed specifically by students from racial and ethnic minority groups.

Notably, social and cultural capital-related "costs" nested within the PMP were most often associated with identifying and securing shadowing experiences.

"People who have family members already in medicine who kind of know the ropes and kind of help with contacts and opportunities, they have a leg up. Because unless you have resources and contacts and things like that, and people who know things for you, it's really difficult to get anywhere in this [premed/admissions]. I feel like they [med school admissions] miss a lot of great people that way because there's some amazing people out there with potential to be great doctors but they just don't have the resources or contacts to get through some of these requirements." (3rd year premed)

"Other students have neighbors and friends of friends or even family that are doctors and they can go shadow them, but I was really stressed about this because I didn't know any doctors - but my mom's boss knew a doctor personally - so I asked him. So crazy that I have to utilize these odd networks to get it done. What about students who aren't able or maybe hesitant to go six degrees of separation to make it happen?" (4th year premed)

These concerns illustrate other important aspects regarding social and cultural capital as well-how information about requirements, opportunities, prep materials, study resources, etc. (i.e., aspects related to cultural capital), is essential to successfully navigate the PMP in a timely manner, and the availability and access to that information. Through the student interviews, specifically those with students from racial and ethnic minority groups, we found that there are significant differences in the amount of information shared to/with these students by majority peers, advisors, and advising groups/organizations (i.e., examples of social capital), along with the timing of when it was received. These information-based disparities had a significant impact on these students' trajectory as they navigated the PMP.

"I think, definitely, for getting also just people of color in the program it's like giving them the resources so that they can understand how to get through. So, I think that giving that information out to everyone, equally. I think it's just a lot of knowing where to go, who to talk to. A lot of people just don't know who to talk to and where to get the information from." (1st year premed)

"But no one told me that from the beginning. There's really no guidance at all. And no one talked to me about research opportunities. I haven't really 
heard about them myself through emails or meetings, I just heard people talking about it, 'Oh yea, I'm doing research, blah blah blah.' But I don't really know how they're doing it. What's the initial steps to do research? I wasn't told about that yet." (3rd year premed)

"I don't know if they [medical school admissions] don't want us [Black students] to be doctors, or if they want to try to make it seem like being a doctor is harder than it is. I'm not exactly sure what their mindset is, but the lack of knowledge and information sharing - that's a huge problem." (3rd year premed)

"I know people, and not to bring race into this or anything, but I know a lot of people here who are African Americans and I'll randomly find out that they're premed, and they're juniors and they don't know about any of the resources on campus. I'm just like 'Okay, who is responsible for getting the information out there?' And it makes me sad because I was fortunate enough to find these resources but there's people here who like...they're so lost, and they're not only not going to get it, they'll just not even apply because they'll realize they are so far behind. I think med schools need to work more closely with undergrad programs." (4th year premed)

As forms of capital are often intertwined, these examples of "costs" associated with social and cultural capital also relate to (extra)curricular capital-as particular types of shadowing experiences (i.e., with whom, where, and how often) and research were seen by interviewees to carry more "currency" with medical school admissions. Further evidence of an (extra)curricular capital within the PMP came as we reviewed how admissions committees view students' GPAs, and how students discussed the "value" associated with pursuing particular courses and academic tracks while on the PMP.

\section{(Extra)curricular capital}

In reviewing medical school admissions procedures and processes, how the admission committees review students' science-specific GPA is reflective of the role(s) of (extra)curricular capital. The "Biology, Chemistry, Physics, Math (BCPM) GPA" is the cumulative average of the applicants' grades in science-specific undergraduate courses (AAMC 2015). Within a students' medical school application, the BCPM GPA is featured with the students' "All Other (AO) GPA" (i.e., average of grades from all "non-science" courses), and the students' overall cumulative GPA. This partitioning of all science-specific grades into a "special" GPA category, as well as the corresponding "All Other" categorization for non-science courses, sends a message to premed students as to what courses have value and carry "currency" with medical school admissions. In short, within the PMP, the courses nested within the BCPM categorization are high in (extra)curricular capital.

To examine the role(s) of (extra)curricular capital more closely, Fig. 1 presents the course "checklist" for students majoring in Biology at the University this study took place compared to the standard list of courses required (and recommended) 

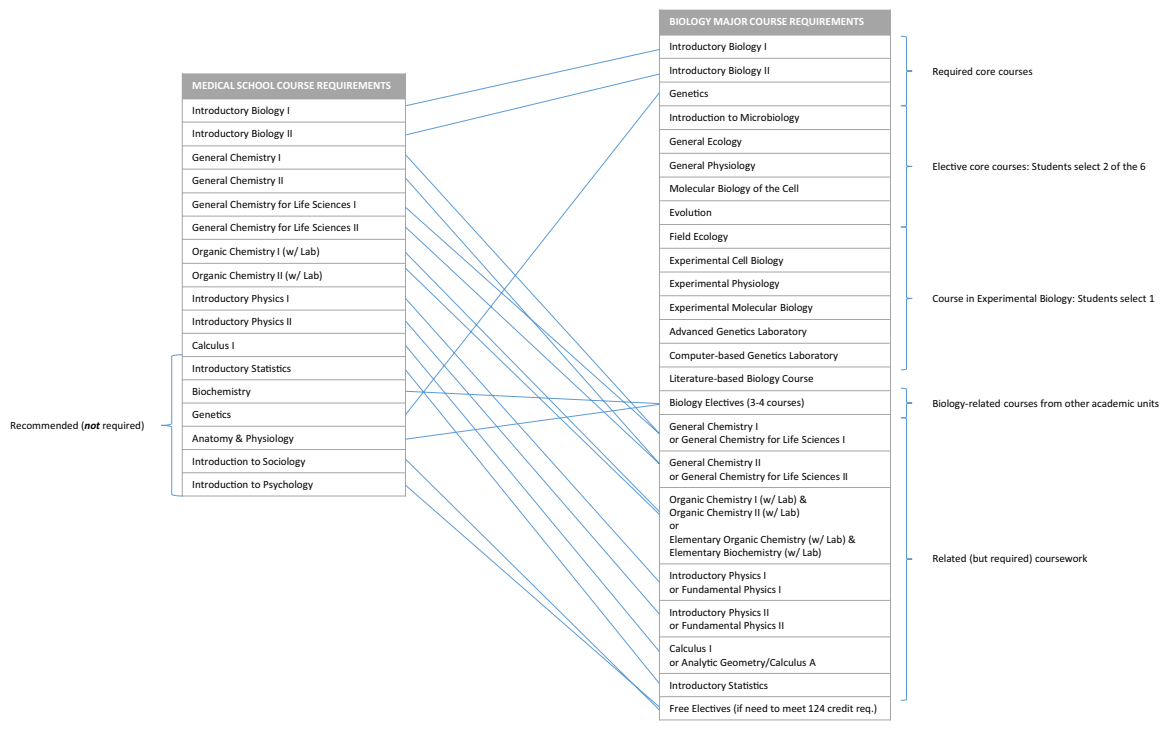

Fig. 1 Comparison of medical school and biology major course requirements
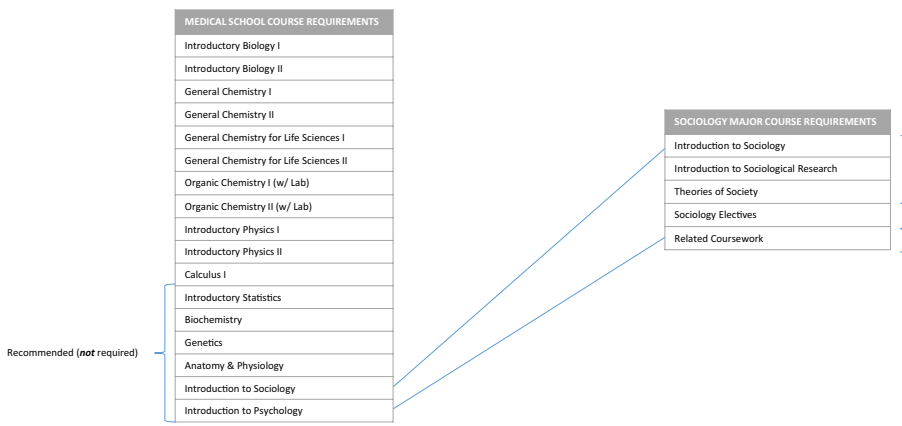

Fig. 2 Comparison of medical school and sociology major course requirements

for applying to medical school. There is considerable overlap between the medical school course requirements and the requirements associated with majoring Biology as a number of required and recommended courses for medical school are actually nested within the Biology-specific courses and acceptable Related Coursework (i.e., "Biology Electives"). Furthermore, the courses nested within the Biology major are also effective in preparing for at least 2 (of the 4) sections of the MCAT (i.e., Chemical and Physical Foundations of Biological Systems (CPBS) and Biological and Biochemical Foundations of Living Systems (BBLS). Moreover, all of the courses associated with the Biology major would "count" towards the BCPM GPA.

Figure 2 presents the requirements associated with majoring in Sociology at the same University compared with the courses required and recommended for 

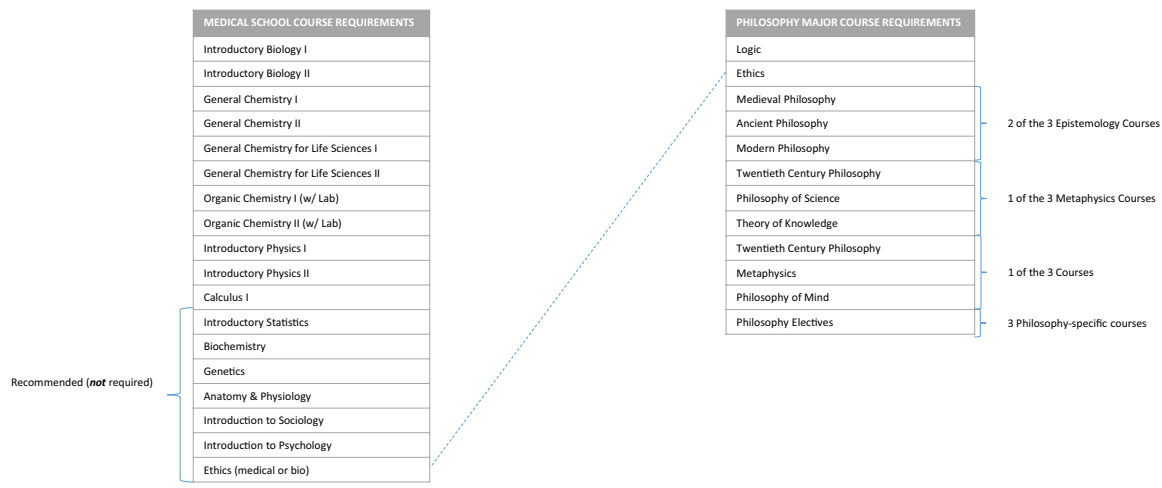

Fig. 3 Comparison of medical school and philosophy major course requirements

medical school admissions. There are no medical school required courses listed on this "checklist," although some of the requirements for this specific major may assist in the preparation for the Psychological, Social, and Biological Foundations (PSBB) section of the MCAT®. Notably, all the courses associated with the Sociology major would be lumped into the "All Other" (AO) GPA.

Similarly, Fig. 3 presents the requirements associated with majoring in Philosophy compared with medical school required and recommended courses. Much like with majoring in Sociology, no courses required for the Philosophy major overlap with medical school required courses. It is unclear whether a general ethics course, such as that required in Philosophy majors, overlaps with ethics courses recommended by medical schools because the latter may need to be more medical or bioethics focused to "count" (hence the dotted line connecting the courses).

As Figs. 2 and 3 suggest, there are significant challenges associated with pursing the PMP and majoring within an SSH discipline such as Sociology or Philosophy. Similarly, during the interviews, the premed students consistently pointed to the challenges associated with engaging with SSH-related majors and the clearer path associated with majoring in Biology:

"I mean, I think it's a very true statement to say that anyone can be premed, any major could be premed. You just need the base requirements, which I think, in hindsight, now that I think about it, all those requirements are built into my Biology major. I actually think people who are other majors are doing the requirements to be premed are doing a little bit more extra work, which is awesome for them because I don't know how they do their major requirements and then almost a whole "nother major on top of it." (3rd year premed)

"Personally, I wanted to do everything. But you can't. You have to optimize. That's why I had to drop my history major. I had to bring up my GPA a little bit because it wasn't where I wanted it to be, and so to get straight A's like I did, I had to cut things out of my life and that's hard to do. I specifically 
ignored friends. And so, there was really nothing except for the requirements themselves for me to do." (4th year premed)

"I feel like we need to have more humanities courses because I feel like a lot of premeds are focused on science courses this, science courses that. It's focused on all these prerequisites, and students kind of...I know that I'm one of them too because I'm so focused on what the med school needs and how to get through in the fastest way." (3rd year premed)

As these exemplary data reflect, majoring in Biology and focusing specifically on medical school science-specific course requirements is a strategic and savvy way of accumulating (extra)curricular capital within the PMP. Correspondingly, the rigidity and structural design of the PMP hinders, if not explicitly discourages, students from engaging with SSH disciplines and/or expanding their scholastic horizons (i.e., academic "well-roundedness") in general.

\section{Discussion}

Pre-professional pathways nested within undergraduate (i.e., college-level) curriculum, such as those for law, business, and medicine (among others), are constructed and sustained in order to cultivate knowledgeable and qualified students who are at least somewhat aware of the profession they are pursuing. In turn, these pathways are certainly "not for everyone," and many students who embark on these pathways may not complete their journeys for any number of reasons (Grace 2017). However, these pathways should be "open" to all interested students, and the challenges embedded in the pathways (e.g., particular requirements, associated costs) should not alienate or discriminate against interested students. The findings from this study suggest otherwise, and that the PMP is indeed an example of discriminatory design in that the "architecture" of requirements and recommendations including (but not limited to) courses, shadowing and volunteering hours, and the MCAT® actually discourages students not steeped in financial social, cultural, and (extra)curricular capital from pursuing and/or continuing the PMP. Moreover, these findings showcase the mediating role of race regarding the influence and impact of forms of capital and spotlight the PMP as situated in and reflective of the broader context of U.S. racial politics and racist culture. Whereas previous research has consistently presented the economic hurdles and pitfalls along the PMP and how these may disproportionately impact students from minoritized and underprivileged backgrounds, our findings spotlight the more implicit costs associated with other forms of capital that also appear to negatively impact students from minoritized groups, including students of color. 


\section{Financial capital}

Our findings reflect previous research showing how students from lower SES backgrounds as well as those from minoritized groups face more economic cost-related barriers and hurdles on the PMP compared to their more privileged peers (Lovecchio and Dundes 2002; Hadinger 2017; De Freitas 2021). Although we presented a lengthy (but non-exhaustive) list of the costs associated with the PMP, the potential expenses associated with even simply preparing for the MCAT ${ }^{\circledR}$ as presented in Table 1 (and not just the MCAT ${ }^{\circledR}$ itself) are quintessential examples of how elements of the PMP related to financial capital create and sustain disparities between and among students. Assuming that resources such as those featured in Table 1 yield even marginal gains, those students from lower incomes and lower SES backgrounds are at an immediate (and consistent) disadvantage, and thereby further distanced from their more privileged peers. Moreover, financial capital can not only impact if, when, and how often students take the MCAT ${ }^{\circledR}$ but also which particular MCAT ${ }^{\circledR}$ score(s) the student sends to medical schools. As there is cost accrued each time a student takes the exam, it may be more cost-effective for some students to simply accept their original scores, which, in turn, could impact their admission to medical school.

Other financial capital-related costs associated with the PMP include participating in study abroad programs (academic and shadowing-based), taking a "Gap" year(s) (AAMC 2020e), taking courses outside of the typical spring/fall semesters (e.g., during winter or summer "breaks"), enrolling in required courses at other colleges in order to prepare for the course at a home institution (e.g., taking Organic Chemistry at a local Community College over a summer), partaking in unpaid medically oriented internships, among other opportunities that can be/are used by medical school admission committees to distinguish "competitive applicants." As is a common theme throughout this study, these opportunities and experiences are exemplary of other forms of capital as well. Moreover, the above discussion does not take into account the need of some students to work full or part-time during their undergraduate/premed years to help fund their college-related costs and living expenses.

\section{Social \& cultural capital}

Evidence of the value and currency of social and cultural capital was apparent in the students' statements regarding identifying and securing shadowing opportunities, as well as acquiring the various types of information necessary to successfully identify, understand, and navigate the PMP. While it is understandable that medical schools want to ensure that applicants have some comprehension of the day-to-day activities of a physician, the presence of liability/privacy issues, restrictions associated with illness-specific seasons (i.e., pre-COVID-19 flu season), crowded clinical arenas, and limited "spots," shadowing opportunities are increasingly difficult for premed students to identify and secure ${ }^{39}$, thus restricting availability and access only to the most "capitalized." Therefore, students savvy in navigating the system associated with shadowing (i.e., high cultural capital), including those with family 
and friends already working within the healthcare industry (i.e., high social capital), have immediate advantages in identifying and securing shadowing opportunities, and completing these particular requirements (and in turn, accruing more (extra) curricular capital). Given the racial, ethnic, and SES-based disparities in the healthcare professions, particularly medicine (Grumbach and Medoza 2008; Capers et al. 2018), students from minoritized groups clearly face more challenges and struggles in acquiring these particular requirement-based opportunities compared to their more privileged peers.

\section{(Extra)curricular capital}

Recent AAMC data highlight how medical school applicants in fact focus their curricular pathway in the sciences with $70 \%$ of all applicants majoring in Biology, Physical Sciences, or specialized health science disciplines (58\% of all applicants majoring in Biology specifically) (AAMC 2019b). Alternatively, SSH majors remain among the lowest number of medical school applicants (12\%: 9\% social sciences and $3 \%$ humanities) and this is in spite of over a century of pushing for a "broad" and "balanced" premedical curriculum that includes explicit representation of the SSH disciplines (Thomas 1978; Bok 1984; Emanuel 2006; Kanter 2008; Gunderman and Lanzieri 2006; Halperin 2010). Whether the recent revision of the MCAT®, with new sections (appearing in 2015), including the Psychological, Social, \& Biological Foundations of Behavior, shifts longstanding patterns favoring the biological and physical sciences remains an empirical question (Roberts et al. 2015; Pritchard 2015). Although Olsen (2016) highlights premedical students' perceived value of sociology and learning social aspects of health and illness in regard to taking an introductory sociology class (specifically tailored for premedical students), it was not clear from our data that students felt a need to act on this shift in the MCAT®. Students in this specific study did not speak to decision-making or strategic engagement with SSH coursework and/or particular shadowing/volunteer opportunities that would align with a knowledge of value/worth associated with this section of the MCAT® in regard to being perceived as a competitive or "unique" applicant. Put simply, the actual influence of the new section of the MCAT® on students' decisions regarding coursework, volunteering, shadowing, etc. remains unclear. As this was not a specific aim of this study, future research could explore if and how students may now acquire (extra)curricular capital that aligns with (particular aspects of) the premise of the new section of the MCAT_-social determinants of health, and structural barriers to health and wellbeing. Are more premedical students majoring or minoring in sociology? Are there new premed-specific clubs or groups focused on examining health inequities and disparities in health and healthcare-and if so, are these "popular"? Are more students addressing or speaking to these issues in their personal statements?

Despite apparent intentions of enhancing the "presence" of SSH in the PMP, findings from this study suggest that the PMP is designed to actively restrict students' choices and opportunities with science-based courses and majors reflecting (extra)curricular capital and thus (implicitly and explicitly) discouraging premedical 
students from engaging in SSH majors and courses-despite formal calls to the contrary. Furthermore, given the association of this (extra)curricular capital with the BCPM GPA, premed students may purposely avoid SSH courses so as "protect" their overall GPA (Simmons 2005).

None of this is to say that premed students are not actually interested in the biological sciences. Rather, our intention is to spotlight that the requirements nested within a Biology major overlap with many (if not all) of the medical school course requirements and recommendations. In this respect, and as Figs. 1, 2, and 3 show majoring in Biology is the path of least resistance. It is a coursework-specific path that is "paved" in that students have the opportunity utilize their (extra)curricular capital to "double-dip" through minimizing the course-load differential between med school requirements and their major. This path of least resistance, in turn, yields more time, "space," and effort to effectively navigate the PMP and identify/ secure other opportunities that could actually accumulate more (extra)curricular capital via shadowing, volunteering, and/or participating in research.

The presentation of the PMP in this sense is somewhat reflective of Armstrong and Hamilton's (2013) "Professional Pathway" model in which they outline how embedded grueling tracking systems, high-stakes testing, academic resources, and opportunities beyond the classroom "..facilitates the conversion of class advantage into academic merit" for students of privilege. Although Armstrong and Hamilton showcase how particular "pathways" nested within undergraduate education and the college experience sustain and reproduce social inequality, our focused discussion of the PMP highlights how a specific professional path is sustained and perpetuated by not only the undergraduate/college organization, but in partnership with professional schools (i.e., medical schools) and overarching governing bodies such as the AAMC.

Taken together, by utilizing the theoretical framework of capital (and, in turn, the distinct but related forms of capital) to examine the primary and secondary data, we not only expand the understanding of the various aspects of financial costs associated with the PMP, but also bring to light the implicit costs associated with the social, cultural, and (extra)curricular capital required to pursue and complete the PMP in a timely manner-and how these capital-based costs are disproportionately felt by students from minoritized groups. Hence, through the lens of capital, it is clear that the PMP is exemplary of discriminatory design.

There are limitations to this study, most notably that the interview data and major course-requirement data were collected from only one undergraduate institution. Future research in this area should not only increase the sample of premedical students, the types of majors (and perhaps include students' minors), but also increase the number and type of undergraduate institutions represented. Moreover, only "active" premedical students were included in this study-students who had stepped off the PMP were excluded. Future research in this area should also include measures for students' financial, social, cultural, and (extra) curricular capital and explore how varying students navigate the PMP, how they confront/respond to particular "costs" peppered throughout the PMP including those who decide never to apply (but who may have indicated an early interest 
via a declared major or membership in some health professions interest group), as well as those who initiated but did not complete application steps.

This study focuses on the PMP specific to the U.S. Although more encompassing future research could compare the structure of and experiences within the PMPs from various countries, given the universal status and prestige of becoming and being a doctor, it is likely that financial, social, cultural, and even (extra)curricular capital play significant roles in other countries' PMPs. In this sense, this theory-driven study provides new insights in the pre-medicine realm in general, regardless of nationality.

Regarding related costs, although the data featured in Table 1 were collected from companies that are popular among the students, there are many more MCAT® preparation companies/sources that could be included in future research. Finally, the theory-driven approach utilized in this study to examine the structure of and experiences within the PMP (i.e., Discriminatory Design, and Capital) may impose an immediate critical assumption onto the study that there are barriers and hurdles for certain students on the PMP. Although this assumption has been presented and supported by previous literature and commentary (such as that cited throughout this paper), an appreciative-inquiry approach to exploring the PMP may lend insights into what processes and mechanisms facilitate and promote "success" among premed students from minoritized groups, as well as those pursing non-typical majors.

\section{Moving forward: addressing the premed curriculum \& engaging the SSH}

Despite calls for the inclusion of SSH into premed curriculum, it is highly unlikely that SSH courses will graduate from "recommended" to required status. Although there are a few medical schools that require such courses for application, the pool of requirements is so saturated that simply adding more requirements will only increase the burden, particularly on (disadvantaged) students. It is also unlikely that particular science-specific courses (e.g., Organic Chemistry) will be removed from the required list. Despite recent studies showcasing their negative impact on women and students of color (Barr 2010; Witherspoon et al. 2019), these courses continue to be used to "weed-out" students, and thus push students off the path (Lovecchio and Dundes 2002). In this sense, many of the science-specific courses, but especially the now somewhat mythical Organic Chemistry, serve as gatekeeping devices for the PMP itself.

Some Universities have retooled courses and/or created new coursework in sociology and psychology, marketing these products to premeds specifically as MCAT® prep-worthy and enhancing the students' well-roundedness (Michalec et al. 2018). However, we argue that such developments only further ostracize the SSH and continue to feed the power differential between medical schools and undergraduate institutions (i.e., the tail is wagging the dog). Furthermore, such premed-specific redesigns of such non-science coursework further isolate premeds from other students and perpetuate the "teaching to the test" mentality as these courses emerged immediately following the recent change in the MCAT®. A more appropriate an 
effective approach to encourage premed students to engage with SSH majors and coursework, according to the students interviewed in this study, would be for premed advisors to work with department leaders in designing explicit curricular pathways that map-out how students interested in SSH can complete premed-, major-, and all college-related course requirements in a timely fashion. Majoring in Sociology, Economics, English, or Philosophy as a premed is not impossible, but it is significantly more challenging - and these challenges can be mapped-out by advisors providing premed students more of a roadmap to success.

\section{Moving forward: addressing the role/impact of shadowing}

In addressing other "costs," we suggest that medical schools (and premed advisors) examine the actual goal(s) of shadowing. Given the challenges in identifying and securing these opportunities, especially for students not steeped in financial, social, cultural, or (extra)curricular capital, (as per the findings of this study) there must be other ways in which premed students can get an understanding of the day-today activities and practices of physicians. Undergraduate nursing education allows up to $50 \%$ of students' clinical education hours to be attained through simulated practice and exercises. Perhaps physicians too can work with simulation programs at educational and care-delivery institutions to develop scenarios that reflect their own work-related experiences. These simulated experiences (complete with pre- and de-brief sessions) would then "count" towards at least some of the shadowing hours requirements. Providing simulated scenarios would not only decrease the pressure associated with attaining shadowing opportunities but also take pressure off clinical facilities and the clinicians themselves. Furthermore, given that the AAMC lists "Service Orientation" as the first Pre-Professional Competency (AAMC 2020f), we also argue there should be less focus on shadowing and a stronger, more explicit focus (i.e., more (extra)curricular capital) on volunteering and community engagement to ensure that volunteering is seen as more than merely checking a box.

\section{Moving forward: expanding theory}

Within this study, we not only showcased the efficacy of employing a theoretical lens to identify and explore processes and mechanisms nested within a social system, but we also highlight the versatility of novel social science-based theories to address previously unexamined phenomena. Given the dearth of "premed is meded" research (Michalec et al. 2018), we advocate for the utilization of appropriate theoretical models (especially those within the social science-based disciplines) to tease out and dissect commonly overlooked and perhaps taken-for-granted policies, practices, and procedures within the PMP. We feel strongly that such an approach is necessary to continue from the discriminatory design perspective and explicitly bring to light the existing evidence of systems-level bias and prejudice, as well as institutional racism within various venues of health professions education. 


\section{Moving forward: opening the gates to the PMP}

There are equal, if not greater, challenges in regard to attracting, retaining, and sustaining students from minoritized groups on the PMP. Large-scale initiatives to alter admissions practices with respect to diversity (specifically in regard to race and ethnicity) have proved unsuccessful. The AAMC's "Project 75," "3000 by 2000," and an additional program aimed at a 30\% increase in enrollment by 2015 have all failed to reach their respective marks (Keith et al. 1985; Marshall 1973; Petersdorf 1992; Cooper 2003; Cohen and Steinecke 2006; Poole et al. 2020). Moreover, Affirmative Action programs utilized by certain medical schools' and undergraduate institutions' admissions boards have been challenged by court cases, and recently, Texas Tech University Health Sciences Center School of Medicine was ordered by the U.S. Department of Education to stop considering race in their admissions (Hartocollis 2019). This order will no doubt have impact on admission practices of other medical schools. Given the current socio-political climate, it will be challenging for medical admission committees/boards to affirm the lasting and lingering effects of structural and institutional racism through explicit action to provide opportunities to those most impacted by institutional and systemic racism brought about through slavery and the Jim Crow era. Nonetheless, we argue that it is necessary and essential in order to address the informal and formal hurdles and barriers outlined above. A first step would be for medical schools to increase the diversity (broadly speaking) of their own admissions committees and boards.

Correspondingly, premed advising and evaluation groups also must address their own diversity (or lack thereof) in terms of composition as well as review their evaluation protocols/practices as they relate to students from minoritized groups. Are they considering the hurdles and barriers discussed above, as well as numerous others nested within the premed path and undergraduate education in general for students of color, first-generation students, as well as students from low SES backgrounds? Importantly, and as emphasized by the students in this study, premed advisors must provide all pertinent and valuable information to all their advisees, particularly those from minoritized groups.

Medical school admissions have attempted to address these issues in-part with holistic review, defined by the AAMC (2020g) as, “...mission-aligned admissions or selection processes that consider a broad range of factors-experiences, attributes, and academic metrics-when reviewing applications." Witzburg and Sondheimer (2013) outline key aspects of holistic review, suggesting that holistic review "... places such measures [aptitude in science] in the broader context of the applicant's life experiences, with particular focus on adversities overcome, challenges faced, advantages and opportunities encountered, and the applicant's demonstrated resilience in the face of difficult circumstances." Nonetheless, although holistic review is intended to align medical schools' mission(s) with their practices, especially in regard to admissions, there are lingering concerns regarding potentially vague metrics, factors, and qualities utilized in the evaluation processes (Conrad et al. 2016; Poole et al. 2020). Furthermore, and as per the crux of this study, with admissions committees and decision-making coming at the end of the PMP, we argue that the process and intention of holistic review, even at its best most effective, come too 
late. Any mission-driven approach to admissions, however appropriate and necessary, must direct remedial attentions to the entire PMP and not just the final "gate." Again, and as we have shown within this study, it is not just one or two "leaky pipes," but the entire plumbing system that needs attention-and scholars and administrators alike must start accepting that the PMP is indeed part of the medical education system.

\section{Moving forward: costs and the PMP}

Medical school, and by extension the PMP, is expensive. Therefore, it is challenging to address the magnitude of financial costs associated with the premed realm and the application process. The AAMC does offer need-based Fee Assistance Programs to help certain students with costs associated with applying to schools, and as noted earlier, many MCAT prep companies offer discounts on their products. Similarly, undergraduate institutions may provide discounted rates for MCAT prep courses, and there are potential scholarships, fellowships, stipends, waivers, etc., that students can apply for that can assist with various aspects of their premed path. Nonetheless, these financial costs remain overwhelming for students and with these relief initiatives still requiring both awareness and successful negotiation of these opportunities. While it may be unrealistic to expect a plurality of schools to adopt the "free" tuition model (Budd 2019), a more inclusive and systems-based approach would be for medical schools to work with test prep companies to reduce costs and fees, as well as to address the costs associated with their school's application and interview process. Nonetheless, even if all medical schools became "free" (truly free) there is still considerable up-front social, cultural, and (extra)curricula PMP-related costs which dissuade many of the very potential applicants medical schools say they are interested in.

\section{Conclusion}

In summary, there are steps both undergraduate institutions and medical schools can take to be more aware of the role(s) of various forms of capital nested within the PMP, and in turn re-design the PMP to be less discriminatory to students from minoritized groups and to smooth the path for those from non-traditional majors. As a necessary first step, both medical schools and colleges need to operationally acknowledge that medical education begins well before medical school, and that the PMP remains both privileging and discriminatory in its structure and processes. In this sense, medical schools (including admissions committees) and colleges (including their health professions advising programs) have an obligation to strategically work with each other to ensure an effective, efficient, inclusive, and sustaining PMP. Reforming the PMP means structurally re-engineering a new pathway, not resurfacing a well-worn street. 


\section{References}

AACOM. n.d. AACOMAS application fees and fee waivers. Retrieved June 17, 2020, from https://help. liaisonedu.com/AACOMAS_Applicant_Help_Center/Starting_Your_AACOMAS_Application/ Getting_Started_with_Your_AACOMAS_Application/02_AACOMAS_Application_Fees_and_ Fee_Waivers.

AAMC. 2015. AMCAS® application course classification guide. Retrieved June 17, 2020, from https:// aamc-orange.global.ssl.fastly.net/production/media/filer_public/e5/68/e5687e03-f55e-4ce6-a4e4892eaab328dc/amcas_course_classification_guide.pdf.

AAMC. 2019a. Table A-8: applicants to U.S. medical schools by selected combinations of race/ethnicity and sex, 2016-2017 through 2019-2020. Retrieved, June 17, 2020, from https://www.aamc.org/ system/files/2019-11/2019_FACTS_Table_A-8.pdf. November 15, 2019.

AAMC. 2019b. Table A-17: MCAT and GPAs for applicants and matriculants to U.S. medical schools by Primary Undergraduate Major, 2019-2020. Retrieved, June 17, 2020, from https://www.aamc.org/ system/files/2019-10/2019_FACTS_Table_A-17.pdf. October 16, 2019.

AAMC. 2020a. Taking the MCAT® exam. Retrieved June 8, 2020, from https://students-residents.aamc. org/applying-medical-school/taking-mcat-exam/s

AAMC. 2020b. 2013-2020 tuition and student fees report. Retrieved June 17, 2020, from https://www. aamc.org/data-reports/reporting-tools/report/tuition-and-student-fees-reports.

AAMC. 2020c. MCAT scheduling fees. Retrieved June 17, 2020, from https://students-residents.aamc. org/applying-medical-school/article/2015-mcat-registration-fees/.

AAMC. 2020d. The cost of applying to medical school. Retrieved, June 17, 2020, from https://studentsresidents.aamc.org/financial-aid/article/the-cost-of-applying-to-medical-school/.

AAMC. 2020e. Making the most of your gap year. Retrieved June 17, 2020, from https://students-resid ents.aamc.org/applying-medical-school/article/making-most-your-gap-year/.

AAMC. 2020f. The core competencies for entering medical students. Retrieved June 17, 2020, from https://students-residents.aamc.org/applying-medical-school/article/core-competencies/.

AAMC. 2020g. Holistic review. Retrieved June 17, 2020, from https://www.aamc.org/services/membercapacity-building/holistic-review.

AAMC Staff. 2018. The official guide to medical school admissions, 2018th ed. Washington, DC: AAMC.

Alexander, C., E. Chen, and K. Grumbach. 2009. How leaky is the health career pipeline? Minority student achievement in college gateway courses. Academic Medicine 84: 797-802.

Armstrong, E., and L. Hamilton. 2013. Paying for the party: How college maintains inequality. Cambridge, MA: Harvard University Press.

Atkin, A.M., R. Green, and L. McLaughlin. 2002. Patching the leaky pipeline. Journal of College Science Teaching. 32: 102-108.

Baugh, A., A. Vanderbilt, and R. Baugh. 2019. The dynamics of poverty, educational attainment, and the children of the disadvantaged entering medical school. Advances in Medical Education and Practice. 10: 667-676.

Barr, D. 2010. Questioning the premedical paradigm. Enhancing diversity in the medical profession a century after the Flexner Report. Baltimore, MD: The Johns Hopkins University Press.

Barr, D., M.E. Gonzalez, and S. Wanat. 2008. The leaking pipeline: Factors associated with early decline in interest in premedical studies among underrepresented minority undergraduate students. Academic Medicine. 83: 503-511.

Barr, D., J. Matsui, S. Wanat, and M. Gonzalez. 2010. Chemistry courses as the turning point for premedical students. Advances in Health Sciences Education. 15: 45-54.

Benjamin, R. 2015, February 5. From park bench to lab bench: What kind of future are we designing? Retrieved October 10, 2018 from YouTube (Tedx Talks). https://www.youtube.com/watch?time_ continue $=2 \& v=\_8 R r X 4 h j C r 0$.

Benjamin, R. 2019. Race after technology: Abolitionist tools for the new jim code. Medford, MA: Polity Press.

Bok, D. 1984. Needed: A new way to train doctors. Connecticut Medicine. 48 (11): 741-748.

Bourdieu, P. 1986. The forms of capital. In Handbook of theory and research for the sociology of education, ed. J. Richardson, 241-258. New York: Greenwood.

Bourdieu, P. 2018. The forms of capital. In The sociology of economic life, eds. M. Grandovetter, R. Swedberg. 3rd ed. New York: Routledge. 
Brewer, J., and A. Hunter. 2006. Foundations of multimethod research: Synthesizing styles. Thousand Oaks, CA: Sage.

Budd, K. 2019, December 2. Will free medical school lead to more primary care physicians? AAMC medical education: Workforce. Retrieved June 1, 2020, from https://www.aamc.org/news-insights/ will-free-medical-school-lead-more-primary-care-physicians.

Capers, Q., L. McDougle, and D.M. Clinchot. 2018. Strategies for achieving diversity through medical school admissions. Journal of Health Care for the Poor and Underserved. 29: 9-18.

Carrington, V., and A. Luke. 1997. Literacy and Bourdieu's sociological theory: A reframing. Language and Education. 11: 96-112.

Cohen, J.J., and A. Steinecke. 2006. Building a diverse physician workforce. Journal of the American Medical Association 296 (9): 1135-1137.

CollegeBoard. 2020. Average estimated undergraduate budgets by sector, 2019-20. Retrieved June 17 , 2020, from https://research.collegeboard.org/trends/college-pricing/figures-tables/average-estim ated-undergraduate-budgets-sector-2019-20\#Key\%20Points.

Coombs, R., and M. Paulson. 1990. Is premedical education dehumanizing? A literature review. Journal of Medical Humanities. 11: 13-22.

Conrad, P. 1986. The myth of cut-throats among premedical students: On the role of stereotypes in justifying failure and success. Journal of Health and Social Behavior. 27: 150-160.

Conrad, S., A. Addams, and G. Young. 2016. Holistic review in medical school admissions and selection: A strategic, mission-driven response to shifting societal needs. Academic Medicine. 91 (11): $1472-1474$.

Cooper, R. A. 2003. Impact of trends in primary, secondary, and postsecondary education on applications to medical school. II: considerations of race, ethnicity, and income. Academic Medicine, 78 (9): 864-876.

Creswell, J.W., V.L. Plano Clark, M. Gutmann, and W. Hanson. 2003. Advanced mixed methods research design. In Handbook of mixed methods in social and behavioral research, ed. A. Tashakkori and C. Teddlie, 209-240. Thousand Oaks, CA: Sage.

Dalen, J., and J. Alpert. 2009. Premed requirements: The time for change is long overdue. American Journal of Medicine 122: 104-106.

De Freitas, C., et al. 2021. Admissions experiences of aspiring physicians from low-income backgrounds. Medical Education. 55: 840-849.

Emanuel, E. 2006. Changing premed requirements and the medical curriculum. JAMA 296 (9): $1128-1131$.

Grace, M.K. 2017. Subjective social status and premedical students' attitudes towards medical school. Social Science and Medicine. 184: 84-98.

Greysen, S., et al. 2011. A history of medical student debt: Observations and implications for the future of medical education. Academic Medicine 86 (7): 840-845.

Groeger, L. V. 2016, September 1. Discrimination by design. Propublica. Retrieved May 15, 2019, from https://www.propublica.org/article/discrimination-by-design.

Grumbach, K., and R. Mendoza. 2008. Disparities in human resources: Addressing the lack of diversity in the health professions. Health Affairs. 27: 413-422.

Gunderman, R.B., and C. Lanzieri. 2006. Opinion: The need for the liberal arts. Journal of the American College of Radiology 3: 904-906.

Hadinger, M.A. 2017. Underrepresented minorities in medical school admissions: A qualitative study. Teaching and Learning in Medicine. 29: 31-41.

Halperin, E. 2010. Preserving the humanities in medical education. Medical Teacher 32 (1): 76-79.

Hartocollis, A. 2019. Texas tech medical school, under pressure from education dept., will stop using race in admissions. The New York Times. https://www.nytimes.com/2019/04/09/us/texas-tech-affir mative-action.html. April 9, 2019. Accessed June 10, 2019.

Hirshfield, L., R. Yudkowsky, and Y. Park. 2018. Pre-Medical Majors in the Humanities and Social Sciences: Impact on Communication Skills and Specialty Choice. 53 (4): 408-416.

Jones, E. 2018. The profitability of racism: Discriminatory design in the Carceral State. 57 U. Louisville L. Rev. 61-103.

Kanter, S. 2008. Toward a sound philosophy of premedical education. Academic Medicine 83 (5): 423-424.

Kaplan. (n.d.a) Cancelling [Your MCAT]. https://www.kaptest.com/study/mcat/how-to-cancel-yourmcat/. Retrieved, June 17, 2020. 
Kaplan. (n.d.b) Retaking [The MCAT]. Retrieved June 17, 2020, from https:/www.kaptest.com/study/ mcat/should-i-retake-the-mcat/.

Keith, S.N., R.M. Bell, A.G. Swanson, and A.P. Williams. 1985. Effects of affirmative action in medical schools: A study of the class of 1975. The New England Journal of Medicine 313 (24): 1519-1525.

Kerr, J.R., and J.J. Brown. 2006. Cost of a medical education: Comparison with graduate education in law and business. JACR. 3 (2): 122-130.

Kitsis, E. 2011. Shining a light on shadowing. JAMA 305 (10): 1029-1030.

Kitsis, E., and M. Goldammler. 2013. Physician shadowing: A review of the literature and proposal for guidelines. Academic Medicine 88: 102-110.

Kvale, S., and S. Brinkmann. 2009. Interviews: Learning the craft of qualitative research interviewing, 2nd ed. Thousand Oaks, CA: Sage.

Lin, K., et al. 2013. The undergraduate premedical experience in the United States: A critical review. International Journal of Medical Education. 4: 26-37.

Lin, K., et al. 2014. What must I do to succeed?: Narratives from the US premedical experience. Social Science \& Medicine. 119: 98-105.

Linnenbring-Garcia, L., T. Perez, M. Barger, et al. 2018. Repairing the leaking pipeline: A motivationally supportive intervention to enhance persistence in undergraduate science pathways. Contemporary Educational Psychology. 53: 181-195.

Lovecchio, K., and L. Dundes. 2002. Premed survival: Understanding the culling process in premedical undergraduate education. Academic Medicine. 77: 719-724.

Marshall, C.L. 1973. Minority students for medicine and the hazards of high school. Journal of Medical Education 48 (2): 134-140.

Michalec, B. 2020. MCAT testing during the COVID-19 pandemic. Academic Medicine. https://doi.org/ 10.1097/ACM.0000000000003526

Michalec, B., and F.W. Hafferty. 2014. Medical Education and the Hidden Curriculum for The WileyBlackwell Encyclopedia of Health, Illness, Behavior, and Society, eds. W.C. Cockerham, R. Dingwall, and S. Quah. Oxford, Blackwell Publishing Ltd.

Michalec, B., et al. 2018. It's Happening Sooner than you think: Spotlighting the pre-medical realm. Medical Education 52: 352-361.

Miles, M., and A. Huberman. 1994. Qualitative data analysis: An expanded sourcebook, 2nd ed. Thousand Oaks, CA: Sage.

Millo, L., N. Ho, and P.A. Ubel. 2019. The cost of applying to medical school-A barrier to diversifying the profession. NEJM 381: 1505-1508.

Morse, J.M. 1991. Approaches to qualitative-quantitative methodological triangulation. Nursing Research 40: $120-123$.

Olsen, L.D. 2016. "It's on the MCAT for a reason": Premedical students and the perceived utility of sociology. Teaching Sociology. 44 (2): 72-83.

Petersdorf, R.G. 1992. Not a choice, an obligation. Academic Medicine 67 (2): 73-79.

Poole, K.G., B.L. Jordan, and M. Bostwick. 2020. Mission drift: Are medical school admissions committees missing the mark on diversity? Academic Medicine. 95: 357-360.

Powell, F. and I. Kowarski. 2020, January 28). 10 costs to expect when applying to medical school. US News \& World Report. Retrieved June 17, 2020, from https://www.usnews.com/education/bestgraduate-schools/top-medical-schools/slideshows/10-costs-to-expect-when-applying-to-medicalschool? slide $=11$.

Prichard, R. 2015. A changing tide: What the new "foundations of behavior" section of the 2015 medical college admissions test ${ }^{\circledR}$ might mean for undergraduate neuroscience programs. Journal of Undergraduate Neuroscience Education. 13 (2): E2-E6.

Roberts, L.W., et al. 2015. Elevating the behavioral and social sciences in premedical training: MCAT2015. Academic Psychiatry 39 (2): 127-131.

Sampson, I., B. Michalec, and F. Hafferty. 2020. Humanism and the premedical realm: An exercise in graphic medical education. Annals of Internal Medicine. 173 (6): W90-W119.

Schindler S. 2015. Architectural exclusion: Discrimination and segregation through physical design of the built environment. Yale L.J. 124, 1934-2024.

Seawright, J. 2016. Better multimethod design: The promise of integrative multimethod research. Security Studies 25 (1): 42-49.

Simmons, A. 2005. Beyond the premedical syndrome: Premedical student attitudes toward liberal education and implications for advising. NACADA Journal. 25 (1): 64-73. 
Steven, K., J. Dowell, C. Jackson, and B. Guthrie. 2016. Fair access to medicine? Retrospective analysis of UK medical schools application data 2009-2012 using three measures of socioeconomic status. BMC Medical Education. 16 (11): 1-10.

Swarthmore. 2020. Frequently asked questions-Applying to med school. Retrieved July 5, 2019, from https://www.swarthmore.edu/health-sciences-office/frequently-asked-questions-apply ing-to-med-school.

Thomas, L. 1978. How to fix the premedical curriculum. New England Journal of Medicine 1298 (21): $1180-1181$.

Walsh, K. 2014. Why is medical education so expensive? Journal of Biomed Research 28 (4): 326-327.

Witherspoon, E., P. Vincent-Ruz, and C. Schunn. 2019. When making the grade isn't enough: The gendered nature of premed science course attrition. Educational Research. 48 (4): 193-204.

Witzburg, R., and H. Sondheimer. 2013. Holistic review-Shaping the medical profession one applicant at a time. NEJM 368: 1565-1567.

Publisher's Note Springer Nature remains neutral with regard to jurisdictional claims in published maps and institutional affiliations. 